\title{
The Influence of Contemporary College Students' Makeup Behavior on Subjective Well-Being: The Intermediary Role of Appearance Anxiety
}

\author{
Qi Pengfei \\ College of Educational Science, Xinlian College, Henan Normal University, Xinxiang, China
}

\section{Email address:}

qpfeel@foxmail.com

\section{To cite this article:}

Qi Pengfei. The Influence of Contemporary College Students' Makeup Behavior on Subjective Well-Being: The Intermediary Role of Appearance Anxiety. American Journal of Applied Psychology. Vol. 10, No. 1, 2021, pp. 16-20. doi: 10.11648/j.ajap.20211001.13

Received: February 9, 2021; Accepted: February 25, 2021; Published: March 3, 2021

\begin{abstract}
Objective: To explore the influence of contemporary college students' makeup behavior on subjective well-being. The intermediary role of appearance anxiety. Method: A survey of 344 college students was conducted using the appearance anxiety scale, makeup behavior questionnaire, and subjective well-being scale. Results: Make-up behavior, appearance anxiety, and subjective well-being were positively related, the more anxious people are about appearance, the more frequent the makeup behavior, and the higher the subjective well-being, subjective well-being is enhanced after the completion of Make-up behavior, but because of the expectation of being praised by the outside world and causing another nature of appearance anxiety. Conclusion: Make-up behavior, appearance anxiety, and subjective well-being are positively correlated, that is, the higher the degree of anxiety about appearance, the more frequent make-up behavior, the higher the requirements. The increase in make-up behavior will lead to more appearance anxiety, but this anxiety can improve subjective well-being may be due to a higher level of social comparison. In other words, when individuals expect to be praised or appreciated by the outside world, they will be more alert to their appearance, which may lead to another nature of appearance anxiety, when their appearance is recognized or better than the previous level of appearance. That is, benefit from make-up behavior, resulting in happiness.
\end{abstract}

Keywords: Make-up Behavior, Subjective Well-being, Appearance Anxiety

\section{Introduction}

In today's society, make-up has generally become an important means of self-image optimization of various groups in society, and an important way for people to enhance their self-identification and gain a sense of self-confidence and achievement. Make-up behavior is an individual through a specific means to make their appearance more in line with the self or social aesthetic operation. Female white-collar workers can use makeup to deal with multiple social crises and enhance their sense of well-being. [1] Make-up can also hide your bad appearance and avoid affecting your mood towards yourself or others, [2] but in the process, another situation may occur: because it is difficult to meet their high standards of beauty, they have a negative evaluation of their bodies, resulting in reduced satisfaction and generate negative emotions. [3] So what is the role of appearance anxiety as an intermediary in the process of happiness caused by make-up?
So far, there has been no discussion on this topic. Therefore, through the investigation of college students, we will discuss the intermediary role of appearance anxiety in the process of make-up behavior and subjective well-being, to better understand the relationship between the three and further explain the mechanism of appearance anxiety effectively to improve the well-being of college students.

\section{Research Review}

\subsection{Overview of Subjective Well-being}

Subjective well-being is a comprehensive psychological experience obtained by individuals based on their own long-term emotional experience and life experience according to certain value standards, and it is a kind of positive and pleasant cognitive evaluation of the value inside and outside the body. Subjective well-being, as a positive psychological quality, is influenced by internal and external 
factors.Individual internal factors: Including genes, personality traits, life satisfaction, health status, etc.External factors may include the social and cultural environment, home school environment, professional work atmosphere, mass media, personal intimacy, economic income, and other factors. In the measurement of subjective well-being, there are mostly two dimensions: overall life satisfaction and specific life area satisfaction.

\subsection{Overview of Appearance Anxiety}

Appearance anxiety refers to the individual's expectation that his or her appearance does not achieve other people's requirements on beauty and produces negative comments about oneself, and people are trapped in an emotional state of anxiety. Because of the social environment for people's appearance requirements and standards, people exposed to the vision of others will be others intentionally or unintentionally observe their appearance and may experience others on their language or non-language attitude evaluation. When individuals with appearance anxiety are observed by others, they feel uneasy, and this anxiety tends to be Self-objectification. People organize or change their appearance to ease anxiety, a long-term, smooth integration in everyday life. However, it does not rule out the emergence of significant events that cause excessive anxiety in themself.Appearance anxiety is influenced by individual self-image and environmental atmosphere [7]

\subsection{Overview of Makeup Behavior}

Make-up behavior refers to the use of cosmetics or other decorative items and tools, according to the target appearance status to choose the appropriate steps and methods, in the Facial features, face, or other parts of the operation, will not meet the target make-up part of the beautification, decoration, cover or will meet the target makeup protrusion, to achieve the desired appearance. Make-up can make our looks more beautiful and increase self-confidence and self-identity [9]Appearance has a significant positive effect on subjective well-being, on the whole, the better the appearance evaluation, the higher the subjective well-being. [10] At the same time, there is a marginal decreasing effect, for the owner of the best appearance, appearance is negative for subjective well-being. [11]

Based on Maslow's demand hierarchy theory and reference group theory to analyze the behavior of makeup: (1) Make-up behavior helps to meet people's aesthetic, cognitive, and self-realization needs; (2) Make-up behavior is the common result of conformity and struggle, through make-up is their image more attractive to others, easy to establish and develop social relations.

This paper analyzes the relationship between make-up behavior and subjective well-being and further discusses the role of gender, age, height, and weight in this process. The prediction and analysis of make-up behavior from the perspective of psychology has important theoretical and practical significance.

\section{Research Methods}

\subsection{Subjects}

In this study, the samples were obtained by combining online and offline and distributed offline in the form of a mobile phone software called Questionnaire Star to major social networking platforms as well as WeChat and QQ groups, and paper questionnaires are distributed offline. A total of 344 questionnaires were distributed, 41 invalid questionnaires were excluded and 303 valid questionnaires were recovered, with a recovery rate of 85.60 percent. The samples were distributed evenly, except for Qinghai province, Tibet Autonomous Region, and Taiwan, where valid data were distributed in other provinces, municipalities, and autonomous regions, of whom 149 were boys, accounting for 45.15 percent, and 153 were girls, accounting for 50.50 percent. The subjects were 14 to 53 years old, with an average age of $24.90 \pm 5.17$ years.

\subsection{Research Tools}

\subsubsection{Makeup Behavior Questionnaire}

The questionnaire was compiled by the author herself, and the makeup behavior was used as a continuous variable to investigate the level of makeup behavior in quantity and quality of the subject group, with a total of 10 questions. The questionnaire has three dimensions, including (1) Satisfaction with your appearance. (2) Use of cosmetics. That is the use of a variety of cosmetics. (3) Make-up frequency and make-up level under different occasions. This includes the frequency and complexity of make-up at home, daily, at ordinary parties, and on important occasions.

\subsubsection{Index of Well-Being, Inedx of General Affect}

The happiness index scale was used to get the level of happiness felt in the latest segment of the subjects. There are two parts: the overall emotional index scale and the life satisfaction questionnaire. The former consists of eight projects that describe the meaning of emotion from different angles, while the latter has only one. The average score of the overall emotion index scale and the score of the life satisfaction questionnaire (weight is 1. 1) Add up to get the total score. The range is between 2.1 (least happy) and 14.7 (happiest). The higher the score, the greater the happiness. The scale has good retest confidence, according to Yao Chunsheng (1995) et al. data, the retest consistency of this scale is 0.849 $(\mathrm{p}<0.001)$.

\subsubsection{Appearance Anxiety Scale-Brief Version}

The scale was compiled by Dion, Dion, and Keelan, it is a questionnaire used to evaluate the level of appearance versus anxiety. The scale, compiled by Dion, Dion, and Keelan, is used to evaluate the level of appearance to the degree of anxiety. The scale includes 14 questions, each item is divided into never, sometimes, often, very many, almost always, scored based on 1, 2, 3, 4, 5. The higher the score, the higher the degree of anxiety about appearance. Domestic researchers have researched on the scale, and the Cronbach coefficient in 
the study is 0.82 . [12]

Table 1. Descriptive statistics of make-up behavior, appearance anxiety and subjective well-being.

\begin{tabular}{llll}
\hline \multirow{2}{*}{ Project } & Population & Comparison of different genders & \\
\cline { 2 - 4 } & $\mathbf{( n = 3 0 3 )}$ & Male $(\mathbf{n}=\mathbf{1 4 9})$ & Female $(\mathbf{n}=\mathbf{1 5 3})$ \\
\hline Make-up behavior & $39.07 \pm 6.32$ & $38.89 \pm 6.00$ & $39.30 \pm 6.61$ \\
Appearance anxiety & $41.50 \pm 8.21$ & $41.42 \pm 7.27$ & $41.67 \pm 9.02$ \\
Subjective well-being & $30.35 \pm 15.68$ & $31.16 \pm 15.06$ & $29.43 \pm 16.25$ \\
\hline
\end{tabular}

Gender as the variable, make-up behavior, appearance anxiety, and subjective well-being as the factor variables, to carry out a one-factor variance analysis. Results As shown in the table, the main effect of sex was not significant on the three factors of makeup behavior, appearance anxiety and subjective well-being $(\mathrm{F}=1.27, \mathrm{p}>0.05)$, i.e. The three do not have a significant impact on gender; A single-factor analysis of age by factor variable showed that the main effect of appearance anxiety was significant $(\mathrm{F}-1.98, \mathrm{p}<0.05)$, indicating that older individuals were more likely to be anxious than younger individuals, but happiness was not significant for age differences (F-1.56, $\mathrm{p}>0.05)$; In terms of weight, the main effects of make-up behavior and appearance anxiety were significant $(\mathrm{F}-1.47, \mathrm{p}<0.05)$, i.e. heavier people were more anxious about appearance than those who were lighter, and there was no significant difference in weight for subjective well-being ("F=1.15, $\mathrm{p}>0.0>5$ ).

Table 2. Analysis of appearance anxiety, makeup behavior, and subjective well-being.

\begin{tabular}{llll}
\hline Variable & $\mathbf{1}$ & $\mathbf{2}$ & $\mathbf{3}$ \\
\hline 1 appearance anxiety & 1 & & \\
2 Make-up behavior & $0.28^{* *}$ & 1 & 1 \\
3 subjective well-being & $0.52^{* *}$ & $0.28^{* *}$ & 1 \\
\hline
\end{tabular}

Note: $* * \mathrm{P}<0.01$

Pearson product-moment correlation was used to correlate appearance anxiety, make-up behavior, and subjective well-being, as shown in the table above, and it was found that there was a significant correlation between appearance anxiety and make-up behavior, between make-up behavior and subjective well-being, or between appearance anxiety and subjective well-being. The higher the frequency of make-up behavior, the higher the subjective well-being, but people are more anxious about their appearance; The happier people feel, the more make-up they do, but the more anxious they are about their appearance; When people become more anxious about their appearance, they also produce make-up behavior, and happiness increases simultaneously after the completion of make-up behavior.

Table 3. The intermediary between cosmetic anxiety and subjective well-being.

\begin{tabular}{llll}
\hline & subjective well-being & Appearance anxiety & subjective well-being \\
\hline Constant & $3.679(0.677)$ & $27.272(9.599 * * *)$ & $-21.298\left(-3.899^{* * *}\right)$ \\
Make-up behavior & $0.683(4.971 * * *)$ & $0.364(5.073 * * *)$ & $0.349\left(2.775^{* *}\right)$ \\
Appearance anxiety & & & $0.916\left(9.445^{* * *}\right)$ \\
$\mathrm{R}^{2}$ & 0.076 & 0.079 & 0.288 \\
Adjust R ${ }^{2}$ & 0.073 & 0.076 & 0.283 \\
Value F & $\mathrm{F}(1,301)=24.714, \mathrm{p}=0.000$ & $\mathrm{~F}(1,301)=25.740, \mathrm{p}=0.000$ & $\mathrm{~F}(2,300)=60.578, \mathrm{p}=0.000$ \\
\hline
\end{tabular}

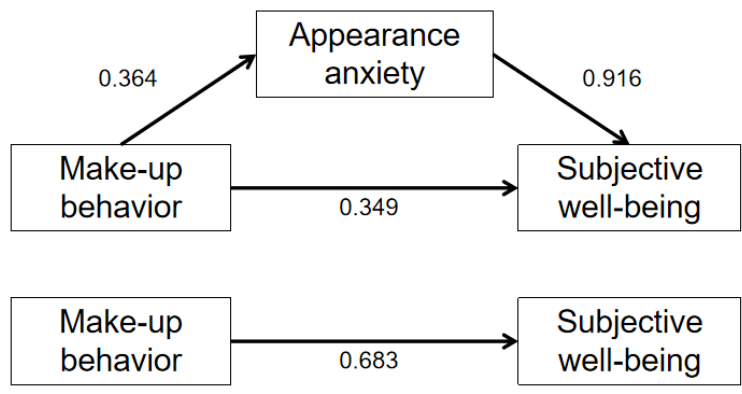

Figure 1. Mediation model diagram.

The results showed that makeup behavior not only predicted subjective well-being significantly positively (c1 s $0.349, \mathrm{p}<0.01$ ), but also increased the regression model's interpretation rate of subjective well-being from 0.076 to
0.288 after adding appearance anxiety, due to regression coefficient a1 (a1 s 0.364, p <0.001), b1 (b1 s 0.916, p<0.001), c1' (c1' s $0.349, \mathrm{p}<0.01)$ are all significant, indicating that appearance anxiety plays a part in the make-up behavior and subjective well-being, The proportion of intermediary effect to total effect is 48.858 percent.

\section{Discussion}

Few studies have explored the relationship between makeup behavior, and subjective well-being. This study focuses on the effect of make-up behavior on subjective well-being and the intermediary effect of appearance anxiety. The research results show that makeup behavior, appearance anxiety and subjective well-being are positively correlated, that is to say, the more anxious people are about appearance, the more frequent they will have makeup behavior, and the 
higher the requirements are. After the implementation of makeup behavior, people's subjective well-being will increase accordingly. In previous studies, [8-9] make-up behaviors that meet the needs of life can make female college students more confident, realize self-worth, and promote individuals to form a better social image. Self-confidence showed a significant negative correlation between anxiety and subjective well-being. [10] Besides, the more positive people's perceptions of appearance, the higher their subjective well-being [11]. Therefore, makeup behavior can better exert one's advantages and present oneself and others in an image that meets spiritual standards. By enhancing self-identity, it can indirectly or directly enhance subjective well-being. However, the reasons for the increase in appearance anxiety are the following points: 1 . Due to the pleasant situation and habits and adaptation, although people's living standards have improved, they are still dissatisfied with the status quo of appearance, resulting in another level of anxiety; [13] 2. Based on social comparison theory From a perspective, [14] when the society of personal life does not have a relatively unified standard of beauty, the social comparison will be used to judge its level and position as a bridge. 3. Influenced by the increasingly diversified network culture, the definition of "beauty" has become more diversified and highly standardized. A survey pointed out that over $60 \%$ of the interviewees have appearance anxiety, and over $50 \%$ of the interviewees have overcome or helped others overcome appearance anxiety. [15] In short, people's makeup behavior will give them attributes that compare with others. Individuals expect to be praised by the outside world or produce a higher level of social comparison to increase their alertness to appearance, which may lead to another nature of physical anxiety, that is, people's make-up behavior and appearance anxiety show a spiral trend. When the appearance is better than the previous level of appearance, people will benefit from the make-up behavior, happiness can be produced again. The descriptive data show that the relationship between make-up behavior, appearance anxiety, and subjective well-being is not significant, the author thinks that because the "beauty" praised by the mass media and the social atmosphere tends to be more similar and demanding, so men and women are popularized the importance of appearance, and the aesthetic needs of external appearance tend to be synchronized. Older individuals have more appearance anxiety than younger individuals, the author believes that this is due to the degree of integration between the individual and the outside world caused by the more mature thinking, more frequent contact with society, the more stringent and unified the standard of "beauty", when the individual is difficult to achieve, it will cause different degrees of anxiety. The improvement of education level has no significant difference in subjective well-being, which may be caused by the more and more identical information people are exposed to due to the popularity of social network media. Compared with traditional media, online media information dissemination has the characteristics of low cost and high efficiency and can realize real-time interaction with netizens. [16]
The variables in this study are closely related to life phenomena and can be used as a reference to control and predict negative emotions such as anxiety, and also to remind people to look at make-up behavior with a developmental perspective, rational analysis of the definition and criteria of their appearance. Also, this study has certain limitations. First of all, the choice of appearance anxiety only applies to the normal population, cannot introduce the prediction and definition of the clinical anxiety category. Secondly, only the questionnaire method is used in the research method, and the experimental method can be added to the later research method to measure the results more realistically and dynamically.

\section{Conclusion}

The higher the frequency of the implementation of make-up behavior, the increase of subjective well-being, but at the same time, appearance anxiety will also reach another attribute of increase, and make-up behavior shows a spiral upward trend, while people's appearance anxiety increases, it may be due to the improvement of the quality of the object or the improvement of living standards, so the subjective well-being will improve again.

\section{References}

[1] Wang Yirui. Analysis on the makeup behavior of white-collar women in China under the influence of makeup fashion [D]. East China Normal University, 2020.

[2] Jin Yan, You Ruihuan. Investigation and Research on make-up behavior of Girls in Junior Middle School [J]. Journal of Campus Life \& Mental Health, 2010, 8 (04): 242.

[3] Zhang Xueyan, Hu Junsheng. The Influence of Self-objectification on Social Anxiety in College Students: The Mediating Role of Body Dissatisfaction [J/OL]. China Journal of Health Psychology: 1-9 [2021-02-23].

http://kns.cnki.net/kcms/detail/11.5257.r.20201015.1056.017.h tml.

[4] Yan Biao-bin, Zheng Xue, Qiu Lin. a study of the factors which influence the subjective ell-beingof college students [J]. Journal Of South China Normal university (Natural Science Edition), 2003 (02): 137-142.

[5] Li Linru, Zhang Jinfu, Liang Xingang. Theory of related factors affecting subjective well-being [J]. Chinese Journal of Mental Health, 2003 (11): 783-785.

[6] Chen Shujuan, Zhou Aibao. A summary of the research on subjective well-being. [J]. Studies of Psychology and Behavior, 2003 (03): 214-217.

[7] Yang Chen, YE Baojuan, TANG Rixin. Effect of Sexual Objectification and Appearance Anxiety on Women's Self-objectification: Moderated Mediation Model [J]. Chinese Journal of Clinical Psychology, 2020, 28 (02): 289-292+325.

[8] Hao Da-hai, Zhu Yue-ting. Adaptation and struggle: a study on the significance of make-up for Contemporary female College students [J]. Youth research, 2016 (06): 69-78+93. 
[9] Sun xu, Zhao Qingwei. Sociological Analysis of make-up behavior of College female students [J]. Business Culture (second half of the month), 2012 (06): 236-237.

[10] Car Liping, Pang Liansheng, Huang Dawei, Zhao Zi-feng. A study on the relationship between Mental Health and confident Personality of College students [J]. Journal of Southwest University (Social Sciences Edition), 2010, 36 (06): 20-24.

[11] Shi Zheng. The Happiness effect of appearance-- an empirical Analysis based on CLDS (2016) [J/OL]. Northwest Population Journal: $1-10$ [2021-02-08]. http://kns.cnki.net/kcms/detail/62.1019.C.20201030.0929.002. html.

[12] Sun Qing-qing. Sexual objectification and self-objectification: model Test and Mechanism Analysis [D]. Southwest University, 2016.
[13] Luo Juan. A Probe into the Improvement of Subjective Well-being [J]. Public Relations World, 2021 (02): 29-30.

[14] Festinger L A. A Theory of Social Comparison Processes [J]. Human Relations, 1954, 7 (2): 117-140.

[15] Wang Kexin. Over $60 \%$ of the interviewees think they have appearance anxiety [J]. Time Post, 2021 (02): 50.

[16] Yin Jueli, Chen Huiying, Wang Jiakun. Negative Public Opinion Propagation Mechanism and Evolutionary Game Analysis in Online Social Networks [J]. Information Science, 2020, 38 (4): 153-162. 10.13833/j.issn.1007-7634.2020.04.023. 